\title{
Hiring and Advancement Hints for Dual Academic Engineering Couples
}

\author{
Noel N. Schulz, Department of Electrical \& Computer Engineering \\ Kirk H. Schulz, Dave C. Swalm School of Chemical Engineering \\ Mississippi State University
}

\section{Introduction}

This paper and presentation will further the authors' previous activities related to dual career hiring [1-2] and address some updated hints for dual career hiring as well as suggestions related to advancement, both within your current university as well as looking at dual career moves to other universities. Hints have been derived from over ten years of experience as a faculty member, search committee member and department head sitting on both sides of the issue. Besides the authors' experience, we have discussed with several other dual career academic couples how they have worked to advance both of their careers.

Hiring new engineering and science faculty is a challenging process. Dual career issues have added an extra layer of challenge to this process. In diversifying faculty, consideration of dual career couples for open faculty positions is essential. A recent National Research Council Survey [3] found that nearly $60 \%$ of all female engineering faculty members had a spouse working in science or engineering. Many articles [4-10] and even one book [11] discuss the issues related to dual career hiring and advancement. A recent study at Cornell University sponsored by the Sloan Foundation found that couples working at the same university are happier and report less stress than those working apart [4]. This study helped quantify issues discussed in an earlier article in the Chronicle of Higher Education [5].

Dual career issues can be accentuated in smaller university towns or cities where the university is the only or one of the only major employers in the area, decreasing other employment opportunities for trailing spouses. In the engineering and related science departments (which include Physics, Math and Chemistry) at Mississippi State University, of the 28 women who have held faculty appointments in the 11 academic units over the past 20 years, 11 have been part of a dual career academic couple. Of the 20 women currently on the faculty, 7 are part of dual career academic couples, with all of the spouses holding or have held faculty appointments within the 11 academic units included in this proposal.

The following sections provide some suggestions related to these topics:

- Hints for Dual Career Couples when Seeking an Academic Position

- Hints for Search Committees Dealing with Dual Career Couples

- Advancement as a Dual Career Couple

- Making it All Work: Balancing Professional and Personal Issues

- Hints for Working in the Same Department 
Hints for Dual Career Couples when Seeking an Academic Position

When seeking dual career academic positions, we have found in our previous work and confirmed through experience some guidelines that should help candidates have the highest probability of success:

- Once one of you is contacted by the Department Head or search committee chair, make that person aware that you are part of a dual career couple. Working out two positions takes time. If you wait until you receive an offer, it may be too late for the university to work out two positions.

- It is critical to work out details of both positions before arriving on campus, including salary, laboratory space, teaching loads, and research start-up funds. Resist the temptation to get this set with one person with an oral agreement on the trailing spouse that "everything will be taken care of when you arrive on campus".

- Talk to dual career couples at your present university to get some suggestions and ideas of how they handled their dual career search.

- Talk with dual career couples at the university where you are interviewing to see how they feel the climate is for couples.

Hints for Search Committees Dealing with Dual Career Couples

While finding a suitable dual career situation is a challenge for many couples seeking academic positions, it is also presents some unique difficulties for search committees. In order to be the most accommodating when attempting to hire dual career couples, we have found several things in particular to be helpful to successfully hiring a dual career couple:

- Always invite the candidate to bring a "guest" with them on their on campus interview. This will allow the candidate to make a more informed decision about the opportunities for both people at your university.

- Put together a schedule of events for the guest. Communicate directly with the guest to try and find out what opportunities they are interested in during their visit. We have had spouses which were interested in working in the elementary schools in the area, were interested in a faculty position in another department, or who simply wanted to get a better feeling for the area.

- Many universities now have some dual career faculty couples. If you are not aware of how your university handles dual career hiring, you might consider contacting some of the dual career couples at your university to find out the mechanics of how their hiring took place. While this is often a "moving target" at many universities, this will at least give you some background on who the key players were in a successful dual career hiring.

- If in your conversations with the candidate, it becomes clear that a tenure track or other university position will be needed to be part of the eventual decision to locate at your university or not, ask for a complete C.V. and contact information. Without some detailed information to look at, it is very difficult to know whom to contact on campus about opportunities for the guest or spouse.

- Involve a person with decision-making authority if a second position will be needed. Depending on whether the additional hire will be in the same department, college, or 
university, you will need to involve the appropriate department head, dean, or provost early enough in the process to ensure that you can make simultaneous or near-simultaneous offers.

\section{Advancement as a Dual Career Couple}

Once the dual career couple has been hired and starts their careers, the next step is to look at advancing as individuals and as a couple. It is very important that the couple talks about each individual's goals. These may change some as your careers evolve. This may also depend on opportunities that become available at your present university.

Moving as a dual career couple has some advantages over the first hiring process. Faculty more advanced in their careers have established a professional reputation and are a more known quantity. However, it is also more challenging as you may have to move two labs, finish graduate students, and complete some research projects. Some thoughts relating to advancement are:

- A dual career couple member may apply a little earlier for a desired administrative position so that they can advance locally without transplanting the spouse. Dual career couples may need to be a little more creative with advancement opportunities within their local university if they do not wish to relocate.

- If you or your spouse is interested in administration advancement, both partners should maintain as marketable a position within your current university as possible. This will help with resources at your current institution as well as for opportunities at other institutions.

- In a move, look for opportunities for both spouses to advance in the new environment. Compare these to your current situation.

- Be careful about moves that only provide good advancement for one of the spouses. A perfect job for one person without a comparable job for the trailing spouse may not be a perfect situation for the couple. If the trailing spouse is unhappy, this may cause problems for all.

- Talk, Talk, Talk! Each couple must work out their arrangements for advancement. Sometimes this may mean temporary separations (NSF or sabbatical). Sometimes this may mean one spouse leads and one follows and the next time, the trailing spouse leads.

Making it All Work: Balancing Professional and Personal Issues

In an NRC profile of female engineering faculty [3], greater than $50 \%$ of the respondents indicated that their career had been negatively impacted when asked about balancing personal and professional issues. This topic is not solely a concern of female faculty, but also a concern of many junior level male faculty members. Additionally the profile found that $57 \%$ of the female engineering faculty had one or more dependents. Several articles have discussed issues relating to having children in academic positions [12-14]. Surprisingly some articles discuss how people who are satisfactorily balancing work and home can help their careers [15-16].

In discussing this topic with other dual career couples, there are several common "themes" that arise which can help couples balance work and family effectively: 
- Hire work out to be done. This can include hiring a nanny if you have children, who can help with getting homework done after school, can transport children to after school activities, and can serve as a babysitter during work related evening events. Additionally, consider hiring someone to come and clean your house a couple times each month. Finally, yard work and construction projects are two other areas where you can often hire someone to do this on a regular basis.

- Don't try to carpool with each other to work. Inevitably, each person will have different meetings to attend, different classes to teach, and different after hours functions. Couples often find it very difficult to carpool in with each other due to vastly different schedules during the day.

- There is no perfect time to have children with two faculty positions. If it is something you want to do as a couple, work it out together.

- Discuss balancing family with professional life with your spouse once you are both employed. This will avoid some unnecessary stress if you divide up the activities at the beginning of the year. In our family, Kirk handles fixing breakfast, kid's athletics, and Boy Scouts, and drops the boys at school several times per week. On the other hand, Noel handles all activities at the boy's schools, Cub Scouts, and coordinating schedules.

- Coordinate travel schedules. Often you can vary work travel enough so that both of you are not out of town at the same time. Typically, with some careful scheduling, we will have only one or two days a year when we are both out of town.

Hints for Working in the Same Department

When discussing dual career issues with other couples, several work in the same department, and had some suggestions and hints on how to be successful while in the same academic unit:

- Be careful about working together too much prior to tenure. It can be difficult to separate technical contributions in papers and research projects during your probationary period. While it is fine to work together, exercise judgment on how much you should do with your spouse or partner

- Create a separate identity for yourself. Do not accept messages, phone calls, or offer opinions for your spouse. When dealing with this issue with office staff, make sure to communicate with them in private how you would like this handled with you and your partner.

\section{Summary}

It is possible for dual career academic couples to both have successful careers. However besides the normal professional challenges, dual career couples often need additional planning as well as continuous communications about their individual goals within the couple environment to make it work. In hiring the keys for couples relate to early communications to the university and getting details in writing for trailing spouses. For search committees, inviting spouses/partners on campus during the interview process and involving the higher administration early in the process are important. For advancement couples must be creative locally to find advancement opportunities, continually re-assess individual goals and make certain that any move has some 
benefits for both people. For balancing personal and professional activities, besides constant communications, couples need to hire services that provide support for household and family activities. For couples within the same department, each faculty member should strive to establish his/her own identify. Often by working through these challenges, the contributions and accomplishments of the couple can be greater than the sum of the parts.

\section{Bibliography}

[1] N.N. Schulz, K.H. Schulz, M.L. Crow and J.L. Drewniak, "Dual Career Academic Searches for Engineering Faculty Positions," Proceedings of the 1996 ASEE Annual Conference, 1996.

[2] N.N. Schulz, K.H. Schulz and M.L. Crow,"A Survey of Dual Career Hiring into Engineering Faculty Positions," Journal of Engineering Education, 86(4), October 1997, pp. 333-339.

[3] National Research Council, From Scarcity to Visibility: Gender Differences in the Careers of Doctoral Scientists and Engineers, National Academy Press, Washington, DC: 2001.

[4] Robin Wilson, "Academic Couples Said to Be Happier Working at the Same University," The Chronicle of Higher Education, 9/2/02, p. A12.

[5] Robin Wilson, "Weary of Commuter Marriages, More Couples in Academe Make Career Sacrifices to Be Together," The Chronicle of Higher Education, 9/20/96, pp. A10-A11.

[6] Rick Perlstein, "Building a Better Spouse Trap," Lingua Franca, March/April, 1996, pp. 14-15.

[7] Laurie McNeil and Marc Sher, "The Dual-Career-Couple Problem," Physics Today, July 1999, pp. 32-37.

[8] C.J. Didion, "Dual Careers and Shared Positions," JCST, November 1996, pp. 123-124.

[9] Vincent Ercolano, "Dual Career Couples," ASEE Prism, April 1997, pp. 28-32.

[10] S.L. Burkett, J.C. Lusth, L.A. Ruhala, R.J. Ruhula, S. Brbsky and B. Hyslop, "Solving the Dual-Career Dilemma: Three Case Studies," Proceedings of the 1999 Annual ASEE Meeting, 1999.

[11] Academic Couples: Problems and Promises, edited by M.A. Ferber and J.W. Loeb, University of Illinois Press, Urbana, 1997.

[12] "Faculty moms: How they do it?", About Women on Campus, Fall, 1998, pp. 4-5.

[13] Robin Wilson, "Timing is Everything: Academe's Annual Baby Boom," The Chronicle of Higher Education, June 25, 1999. pp. A14-A15.

[14] Mairin B. Brennan, "Women Chemists Reconsidering Careers at Research Universities," Chemical \&Engineering News, June 10, 1996, pp. 8-15.

[15] Joann S. Lublin, "Working Dads Find Family Involvement Can Help Out Careers," The Wall Street Journal, Tuesday, May 30, 2000.

[16] Leslie Kaufman (NY Times), "Workers slow down - and their bosses like it," Milwaukee Journal Sentinel, May 9, 1999, p. 2D.

\section{Biographical Information}

Noel N. Schulz. Professor Schulz is currently an Associate Professor of Electrical and Computer Engineering at Mississippi State University. Prior to teaching at Mississippi State, she was on the faculty at Virginia Tech, the University of North Dakota, and Michigan Technological University. She is active in the IEEE Power Engineering Society and ASEE. E:mail: schulz@ece.msstate.edu

Kirk H. Schulz. Professor Schulz is currently the Director of the Dave C. Swalm School of Chemical Engineering at Mississippi State University, and is the holder of the Earnest W. Deavenport Jr. Chair in Chemical Engineering. Prior to teaching at Mississippi State, Dr. Schulz was on the faculty at Michigan Technological University and the University of North Dakota. He can be reached via email at schulz@che.msstate.edu. 